\title{
Range, Activity, and Habitat of Large, Free-Ranging Brown Trout in a Michigan Stream
}

\author{
David F. Clapp ${ }^{1}$ and Richard D. Clark, JR. \\ Michigan Department of Natural Resources, Institute for Fisheries Research \\ Ann Arbor, Michigan 48109-1084, USA
}

JAMES S. Diana

School of Natural Resources, The University of Michigan Ann Arbor, Michigan 48109-1115, USA

\begin{abstract}
Little is known about behavior patterns and habitat use of large $(400+\mathrm{mm}$ total length) brown trout Salmo trutta. We used radio telemetry to monitor the movements of eight large (437-635 mm), free-ranging brown trout for up to $346 \mathrm{~d}$. Total range of movement upstream and downstream varied from $370 \mathrm{~m}$ to $33,420 \mathrm{~m}$. At some time during the year, six of the fish moved out of an area protected with no-kill fishing regulations, even though none of them were tagged and released closer than $\mathbf{2} \mathrm{km}$ from its boundaries. However, four of five fish tracked during the height of the fishing season spent $87 \%$ of their time in the protected area. The fish appeared to have separate winter and summer ranges. Five of six fish tracked during autumn-winter moved upstream about $10 \mathrm{~km}$ to slower, deeper parts of the river between August and November, and remained there at least through the following April. The part of the river used as autumn-winter range was considered only marginal habitat for brown trout during summer due to warm water temperatures. Individuals used as many as four specific home sites within their spring-summer range; average separation between home sites was $386 \mathrm{~m}$. The fish typically rotated among sites, spending 2-3 d at one site before moving, usually at night, to another section of river. Activity was divided into two categories: active displacement-long-range travel from one part of the range to another; and foraging - short-range movements that might occur when searching for food. Active displacement appeared to be correlated with stream discharge. Fish displaced themselves an average of $239 \mathrm{~m}$ between telemetry observations in spring-summer and 3,103 $\mathrm{m}$ in autumn-winter; only $11 \%$ of this variation was attributable to variations in the length of time between telemetry observations in spring-summer and autumn-winter. Daily foraging activity varied by month and appeared to be related to light level, food availability, and water temperature. In spring-summer, fish typically moved to midstream to forage at night, then retumed to cover at specific home sites during the day. The sites they selected in daytime were characterized by deep $(>30 \mathrm{~cm})$, slow $(<10 \mathrm{~cm} / \mathrm{s})$ water with heavy log cover and silt substrate.
\end{abstract}

The life history and behavior of stream-dwelling brown trout Salmo trutta have been studied extensively, but most of the research has focused on fish less than $\mathbf{4 0 0} \mathrm{mm}$ long. Brown trout longer than $400 \mathrm{~mm}$ are relatively rare in streams and difficult to observe directly. Nevertheless, these large fish are important components of many recreational fisheries, because many anglers are motivated by the possibility of catching them. Fisheries management activities, such as habitat improvement or restrictive fishing regulations, are sometimes intended to increase the number of large fish in a stream. Yet little is known about the behavior or habitat requirements of large brown trout.

\footnotetext{
I Present address: Florida Game and Fresh Water Fish Commission, 601 West Woodward Avenue, Post Office Box 1903, Eustis, Florida 32727, USA.
}

Many behavioral traits are size dependent, and some evidence suggests that the largest adults represent a unique stage in the life history of brown trout (Shetter 1968; Jenkins 1969; Alexander 1977; Stauffer 1977). In a mark-and-recapture study, Shetter (1968) found that brown trout longer than $356 \mathrm{~mm}$ moved greater distances than smaller fish; one large brown trout was recovered $64 \mathrm{~km}$ from its tagging site. Shetter (1968) hypothesized that large fish were more mobile than small ones because the living space and food preferred by these large brown trout are limited resources. The few large brown trout $(400+\mathrm{mm})$ observed by Jenkins (1969) spent most of their time hiding in dense cover and only occasionally moved into his observation area. He suspected that these fish were primarily piscivores and had definite refuge positions and daily ranges for their foraging.

Diet studies have shown that brown trout tend to shift their primary food source from insects to 
fish at about the same size, $350-400 \mathrm{~mm}$, that Shetter (1968) and Jenkins (1969) observed them to increase movement. For example, Stauffer (1977) found that stomachs of 76-152-mm brown trout from the South Branch of the Au Sable River contained $100 \%$ invertebrates, whereas stomachs of 152-254-mm brown trout contained $93 \%$ invertebrates and $7 \%$ fish by volume. In another study on the North Branch of the Au Sable River, Alexander (1977) found that the diet of brown trout larger than $305 \mathrm{~mm}$ was composed of $25 \%$ invertebrates and $75 \%$ fish by weight.

It seems likely that these size-dependent changes in movement and feeding could be related to the economy of living in a river. A number of studies have shown that brown trout smaller than $\mathbf{4 0 0}$ mm are stationary, drift feeders (Allen 1951; Jenkins 1969; Solomon and Templeton 1976; Bachman 1984). However, Jenkins (1969) hypothesized that fish hold feeding positions in the current only as long as the positions supply an adequate amount of food. He suggested that this would lead larger brown trout to roam in search of more economical feeding positions and eventually cause them to change from a diet of insects to fish, and return to insects only during the most favorable feeding conditions (such as a hatch of large aquatic insects). He also suggested that this behavior would be restricted to larger, dominant fish because of their aggressive superiority, and the freedom it gives them of unchallenged movement in the stream.

To help answer the question of how much food is adequate for drift-feeding salmonids, Bachman (1982) developed a mathematical model based on the energetics of foraging in a stream. This modeling exercise supported Jenkins' (1969) hypothesis. Bachman (1982) found that size-dependent increases in metabolic cost should combine with natural food limitations to impose constraints on growth for drift-feeding fish. He further hypothesized that these growth constraints should lead brown trout to adopt a piscivorous feeding strategy. His observations of brown trout in a Pennsylvania stream supported the idea that growth would be constrained (Bachman 1984). The driftfeeding brown trout he observed were less than $350 \mathrm{~mm}$ long and grew slowly. Although Bachman (1984) did not observe any fish switching to piscivory, the studies of diets mentioned earlier have provided ample evidence that most large brown trout do eat fish. However, the specific details of brown trout behavior and habitat use once this switch to piscivory is made are still unknown.
The purpose of our study was to document the total range of movement, activity patterns, and habitat use of large, wild brown trout in the South Branch of the Au Sable River, Michigan. We chose exceptionally large fish for this study (437-635 $\mathrm{mm}$; all lengths mentioned in this paper are total lengths), near the maximum size for brown trout in this river, and tracked them with radio telemetry gear. Radio telemetry helps overcome some of the difficulties inherent in studying the habits of rare, mobile animals (Winter 1983). We interpreted our findings in the context of some important management issues, such as defining habitat suitability and determining the minimum effective size of areas with special fishing regulations.

\section{Methods}

Study area. - The South Branch of the Au Sable River extends $78 \mathrm{~km}$ from Lake St. Helen to the main stem of the Au Sable River (Figure 1). There is only one dam on the South Branch (about $3 \mathrm{~km}$ below Lake St. Helen), so fish are free to move almost the entire length of the river. However, dams on the Au Sable River main stem prevent fish from migrating to Lake Huron. We worked primarily in a 23-km section of river between Kilmer Road and Smith Bridge. Two small tributar-

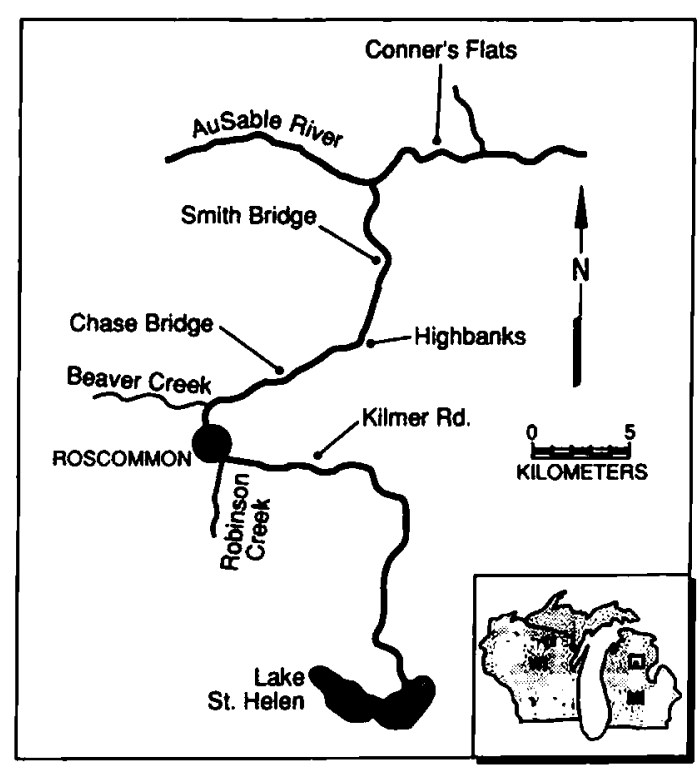

Figure 1.-South Branch of the Au Sable River, Michigan. Brown trout were collected for implants of transmitters between Chase Bridge and Highbanks. Insert shows states of Michigan (MI) and Wisconsin (WI) and location of detailed map; a dot represents the town of Roscommon. 
ies in this area could also hold brown troutBeaver Creek and Robinson Creek.

Lake St. Helen, the source of the South Branch, is a warmwater lake, but water in the river cools as it flows downstream due to gradually increasing inputs of groundwater. Coopes (1974) reported that maximum summer water temperatures gradually decreased from $30^{\circ} \mathrm{C}$ near Lake St. Helen to $21^{\circ} \mathrm{C}$ at Smith Bridge. The section of river from Kilmer Road to Chase Bridge is a transition area between a warmwater stream and a coldwater trout stream. This unusual temperature gradient along the length of the South Branch (upper reaches warm and lower reaches cold) may influence the movement of brown trout.

The predominant fish species in different areas of the river generally reflect the temperature gradient. In the Lake St. Helen-Kilmer Road section, northern pike Esox lucius, yellow perch Perca flavescens, suckers Catostomus spp., and minnows (Cyprinidae) were the primary fishes (Shetter 1968). Below Roscommon, brown trout and brook trout Salvelinus fontinalis were the primary fishes, and brown trout made up about $85 \%$ of the trout standing stock by weight at Chase Bridge. The study area of the South Branch has not been stocked with hatchery trout since 1973.

Mean annual flow of the South Branch was recorded at Smith Bridge as $6.5 \mathrm{~m}^{3} / \mathrm{s}$ (Coopes 1974). Average width of the river through our study area was about $20 \mathrm{~m}$, and average gradient was $0.09 \%$ (Shetter 1968).

The South Branch had three different sets of fishing regulations for brown trout along its length during our study. From Lake St. Helen to Chase Bridge, normal statewide regulations were in effect. There, fishing was permitted with any lure or live bait from the last Saturday in April through September 30, with a minimum size limit of 203 $\mathrm{mm}$ and a daily creel limit of 10 fish. From Chase Bridge to Highbanks $(7.2 \mathrm{~km})$ no-kill, catch-andrelcasc rcgulations were in effect (harvest was prohibited), and flies-only fishing was permitted from the last Saturday in April through October 31. From Highbanks to the river's mouth, flies-only fishing was permitted; the minimum size limit was $254 \mathrm{~mm}$, and the daily creel limit was five fish. One objective of our study was to evaluate the movements of large brown trout in relation to the size of areas protected by the most stringent fishing regulations.

Implanting transmitters. - Wild brown trout were captured with DC-electrofishing gear in the no-kill fishing area between Chase Bridge and
Highbanks. Fish were anesthetized with tricaine (MS-222), and an incision was made into the abdominal cavity either through the lateral body wall or ventrally, anterior to the pelvic girdle. A radio transmitter was inserted through the incision, and the incision was closed with non-dissolving nylon sutures. Fish were immediately released near the site of capture.

Radio transmitters, each including an internal loop antenna, were $4 \mathrm{~cm}$ long and $2 \mathrm{~cm}$ in diameter. Their weight varied with battery size; 12 $\mathrm{g}$ for those used in 1986 and $20 \mathrm{~g}$ for those used in 1987. Transmitter batteries used in 1986 failed after about 3 months, earlier than expected, so they were replaced with larger batteries in 1987 . These larger batteries lasted at least 12 months. Each transmitter was encased in surgical wax and bore identifying information, including a telephone number to call in case one of the fish was found dead or was caught by an angler. Each fish was tracked on a different frequency between 49 and $50 \mathrm{MHz}$.

Locating fish. - No more than three fish with transmitters were simultaneously at large. From May 1 through August 31, we attempted to locate all fish every other day. These telemetry observations were generally made between 0600 and 2200 hours. On the alternate days, we selected one or two fish to monitor continuously for analysis of foraging activity. From September through April we located fish about once every 2 weeks. Fish recovering from implant surgery sometimes exhibit erratic behavior (Mesing and Wicker 1986), so we allowed 2 weeks for recovery before recording any data on fish movements.

We used a scanning receiver (Challenger 200, Advanced Telemetry Systems, Isanti, Minnesota) with two interchangeable directional loop antennas, one $60 \mathrm{~cm}$ in diameter for long-range work and one $15 \mathrm{~cm}$ in diameter for close-range work. Fish could be detected at a maximum distance of about $200 \mathrm{~m}$ with the $60-\mathrm{cm}$ antenna. Wc werc sometimes able to locate fish near their previous locations by walking to these sites. When fish moved long distances, it was necessary to use a canoe to locate them. Searches for fish covered the area from Kilmer Road to Conner's Flats. No search was conducted on the Au Sable River main stem upstream of its confluence with the South Branch.

Using triangulation, we were able to determine the position of a fish to within a 4- $\mathrm{m}^{2}$ area. This degree of accuracy was verified early in the study by wading into the river until the fish was seen. 
After this initial verification, we tried not to disturb fish, except to make habitat measurements. Fish usually remained near or in cover at their original position even as habitat measurements were taken. We assumed that the presence of the observer during these habitat measurements did not significantly influence the later movement or behavior of the fish. We do not think that fish could detect the presence of the observer during our observations of fish activity.

For analysis of range and activity, location data were separated into two time periods, spring-summer (May 1-August 15) and autumn-winter (August 16-April 30). Mid-August was selected as the division between time periods, because field observations suggested that large brown trout began to exhibit more extensive long-range movements at this time. Two large brown trout were tracked exclusively during the spring-summer period (May-August 1986), three fish were tracked exclusively during the autumn-winter period (October 1986-February 1987), and three fish were tracked through both periods (June 1987-May 1988).

Range. - We charted the total range of the large trout, and the frequency with which they occupied different parts of their range. Total range was defined as the distance between the extreme upstream and downstream sites in which a fish was located. A Wilcoxon rank-sum test (Walpole and Myers 1985) was used to determine whether differences between mean values for summer and winter ranges were significant. We used simple linear regression to determine whether a relationship existed between the number of days a fish was tracked and the size of that fish's range.

Maps were constructed from aerial photographs and topographic maps and used to partition the river into 10 -m-long segments. Home sites within a fish's range were identified for those fish tracked during spring-summer. A home site was broadly defined as one of the $10-\mathrm{m}$ segments of river in which an individual was located five or more times, or a previously used segment to which a fish returned after an extended absence (thus exhibiting a homing tendency). Home sites could have been defined more precisely as specific cover structures within the range where individual trout were located repeatedly, because brown trout were nearly always stationed in exactly the same cover structure within a given $10-\mathrm{m}$ segment. Home sites were not defined for fish tracked during autumnwinter due to the small number of telemetry observations.
Activity. - Activity was divided into two categories that represented two different kinds of behavior: active displacement and foraging. Active displacement represented longer movements from one part of a fish's range to another, or between summer and winter ranges. It was measured as the distance a fish traveled between successive locations. We regarded this as a minimum estimate of movement, in that it included only the absolute change in position from one daytime resting place to another and did not necessarily include the total distance a fish might have traveled between successive telemetry observations. Average active displacement was computed for individual brown trout, and for combined groups of fish tracked during spring-summer and autumn-winter periads. Differences were examined by a KruskalWallis test (Walpole and Myers 1985). A simple linear regression was used to determine whether any relationship existed between distance of active displacement and days between successive telemetry observations. Frequency distributions of upstream and downstream displacement distances were developed for spring-summer and autumn-winter periods, and comparisons between these distributions were made with a Kolmogorov-Smimov test (Sokal and Rohlf 1969).

Foraging, the second activity category, included shorter movements that might occur when a fish was searching for food or interacting with other animals. This activity was detected from fluctuations in radio signal strength, as measured by an ammeter on the radio receiver. An activity level of 30 signal fluctuations/min of observation (equivalent to the transmitter pulse rate) was assumed to represent continuous motion by the fish. We determined that the fluctuations were actually caused by movement of a fish and were not background "noise" by observing the signal response from a transmitter placed in a dead fish, which we moved around in the river manually. These tests were monitored with a chart recorder that was attached to the radio receiver, in addition to the usual ammeter. Changes in the distance, depth, or orientation of the fish in relation to the antenna caused the signal fluctuations in these tests.

Because foraging activity can vary in response to seasonal changes in day length, water temperature, and food availability (Chaston 1969), we grouped the measurements by month. Daily foraging cycles were documented during June, July, and August, and to help interpret the cycles, maximum-minimum thermometers were placed in the river near the area where most of the foraging 
activity occurred. Mean maximum and mean minimum water temperatures were calculated for each month.

To monitor foraging activity, we divided a day into 2-h (1986) or 3-h (1987) periods. The periods were then selected at random as observation periods such that a complete 24-h cycle was covered every two weeks. Two brown trout, at large simultaneously, were monitored for foraging activity in each year of the study.

During each observation period, foraging activity was measured by mounting the receiving antenna on a tripod within signal range of the target fish. The number of fluctuations in signal strength was recorded over a 1 -min interval, once every 5 min. We then computed, by month and year, the mean number of fluctuations per minute for each hour of the day. We tested for differences between months and years with a two-way analysis of variance (ANOVA).

Habitat. - Our habitat analysis was designed to test the hypothesis that large brown trout select habitat with specific characteristics, as opposed to selecting habitat at random. Thus, we measured and compared habitat used by the fish to the overall habitat available to them. We concentrated on habitat used in the daytime hours of spring-summer, or "daytime refuge sites."

To assist in analysis of habitat, we divided each of the 10-m river segments defined above for analysis of range into two 5-m-wide quadrats, measured from opposite banks towards the middle of the river. The river was wider than $10 \mathrm{~m}$ in most cases, so this grid system did not include the center of the river. However, the brown trout were never located in the center of the river (outside the grid system) during the daytime. The size of the quadrats represented an area large enough to ensure that the actual position of the fish was encompassed in its boundaries, considering the accuracy of triangulation, and small enough such that meaningful habitat data could be collected.

Habitat was described in 18 river quadrats used by three large brown trout during daytime hours from May through August 1987. Fish often used the same quadrat numerous times at different discharge levels, so 6 of the 18 quadrats were measured more than once to represent this range of conditions. To describe overall habitat within each quadrat, we established transects perpendicular to the current at the quadrat's upstream edge, middle, and downstream edge. Habitat variables were measured at $1-m$ intervals along each transect, for a total of about 15 measurements in each quadrat.
Water velocity was measured at two points at each $1-\mathrm{m}$ interval; at $0.6 \times$ water depth at the interval and $1-5 \mathrm{~cm}$ above the bottom. A Swoffer 2000-1 Open Stream current meter was used.

Predominant substrate type at each interval was categorized by visual observation as silt, sand, gravel ( $<2 \mathrm{~cm}$ diameter), small cobble $(2-10 \mathrm{~cm}$ diameter), or large cobble ( $>10 \mathrm{~cm}$ diameter). This classification system was a modification of the one described by Orth (1983), in which we condensed his 11 particle-size classifications into 5 .

Cover type was categorized as logs, brush, vegetation, boulders, overhang, or open. Logs provided instream structure for fish, and included trees, limbs, boards, and combinations of these items that were greater than $10 \mathrm{~cm}$ in width or diameter. Brush, primarily tree tops lying in the water or flooded riparian vegetation, also provided instream structure but included no individual branches greater than $10 \mathrm{~cm}$ in diameter. The vegetation category included rooted aquatic vegetation, primarily Elodea canadensis and Vallisneria americana. Overhang provided no instream structure, but shaded fish from sun or overhead disturbances. Overhang usually comprised logs, boards, or brush that did not significantly penetrate the surface of the water. Open areas provided essentially no cover.

Similar habitat measurements were taken for 19 river quadrats chosen at random from within the known range of the large brown trout. Some of the randomly selected quadrats were the same ones the fish had used, but the intent was to obtain a sample of all available habitat to compare with a sample of the habitat actually used.

Two frequency distributions were developed for each habitat variable with data from the individual transect measurements. One frequency distribution represented the combined habitat present in the quadrats used by the fish, and the other represented the combined habitat present in quadrats within the known range. We used an $L$-test (Strauss 1979) to detect significant differences between the distributions.

\section{Results}

\section{Implanting Transmitters}

Surgical implantation of radio transmitters was successful for eight brown trout. The fish ranged in size from 437 to $635 \mathrm{~mm}$, and were tracked for periods of 52-346 d (Table 1). Transmitters did not appear to affect the behavior of these fish. Radio-tagged fish were observed surface feeding 
TABLE 1.-Summary of successful transmitter implants in brown trout in the South Branch of the Au Sable River on three dates in 1986-1987.

\begin{tabular}{cccc}
\hline Fish number & $\begin{array}{c}\text { Length } \\
(\mathrm{mm})\end{array}$ & $\begin{array}{c}\text { Weight } \\
(\mathrm{g})\end{array}$ & $\begin{array}{c}\text { Days } \\
\text { tracked }\end{array}$ \\
\hline 1 & \multicolumn{2}{c}{ May 5, 1986 } \\
2 & 437 & 830 & 52 \\
& 488 & 1,112 & 102 \\
3 & & Oct 23, 1986 & \\
4 & 589 & 1,850 & 80 \\
5 & 521 & 1,550 & 114 \\
& 635 & 2,050 & 93 \\
6 & & $J$ Jn 3, 1987 & \\
7 & 510 & & 199 \\
8 & 505 & & 346 \\
\hline
\end{tabular}

on large mayflies (primarily Hexagenia limbata) and fleeing from animals (such as white-tailed deer Odocoileus virginianus) entering the stream at night. One fish was observed on a spawning redd. We recaptured this same fish at the end of the study and examined its surgical incision. The incision had healed well, and the fish was in excellent condition. It was able to elude an electrofishing crew for almost an hour with rapid bursts of swimming for $50 \mathrm{~m}$ or more at a time. Tracking of all fish ceased when transmitter batteries failed, except for fish number 1 which was tracked for only $52 \mathrm{~d}$ (Table 1 ). We suspect that this fish was taken illegally by a poacher.

We implanted transmitters into 16 other brown trout that died. Seven of these fish died within 24 $h$ of surgery, and the remaining nine died within 2 weeks. Mortality seemed to be related to the site of surgical incision on the fish and the prevailing water temperature. Brown trout experienced $75 \%$ mortality (15 of 20) when transmitters were implanted through incisions in the lateral body wall, but only $25 \%$ mortality ( 1 of 4 ) after ventral implants. The only mortality after a ventral implant occurred when water temperature was $20^{\circ} \mathrm{C}$. When water temperatures were above $18^{\circ} \mathrm{C}$, all fish died within a few hours of surgery, regardless of the site of surgical incision.

\section{Range}

Range size varied among individuals, from 370 to $33,420 \mathrm{~m}$ (Figure 2). There was no significant difference $(P<0.05)$ in the average size of total ranges for spring-summer versus autumn-winter. The average range $( \pm 2 S D)$ was $4,935 \mathrm{~m}( \pm 15,876)$ for four fish tracked during spring-summer, and $11,902 \mathrm{~m}( \pm 30,324)$ for four fish tracked during

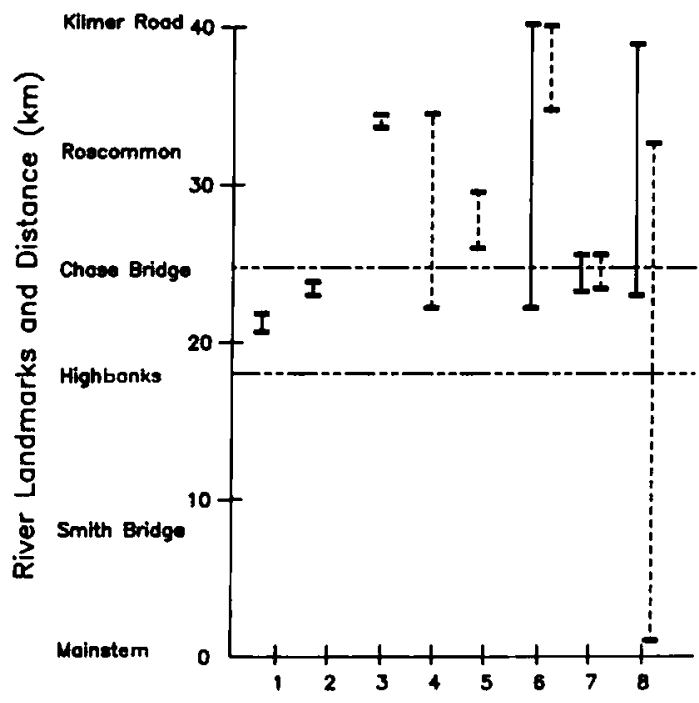

Fish Number

Figure 2. - Total range of movements by eight brown trout tracked during our study. The catch-and-release fishing area (fies-only, zero creel limit) is demarcated by horizontal dashed lines. Upstream and downstream limits of fish movements are indicated by upper and lower horizontal bars. Vertical solid lines between horizontal bars indicate spring-summer range of movement; vertical dashed lines indicate autumn-winter range of movement.

autumn-winter. There was no significant relationship between the number of days a fish was tracked and the size of that fish's range.

The large brown trout clearly did not move at random. They were located in only a few of the many 10-m river segments that made up their total range (Figure 3). Three of the fish tracked in spring-summer (numbers 1, 2, and 7) had four home sites that were separated by an average distance of $386 \mathrm{~m}$ (Table 2; Figure 3). The fish were located at these home sites in $86-97 \%$ of the daytime telemetry observations.

These same three trout typically rotated their

TABle 2.-Spring-summer home site use by large brown trout. Number of observations is the number of times fish were located with telemetry gear. Mean separation is the average distance between home sites.

\begin{tabular}{ccccc}
\hline $\begin{array}{c}\text { Fish } \\
\text { number }\end{array}$ & $\begin{array}{c}\text { Number } \\
\text { of obser- } \\
\text { vations }\end{array}$ & $\begin{array}{c}\text { Number } \\
\text { of home } \\
\text { sites }\end{array}$ & $\begin{array}{c}\text { Mean } \\
\text { separation, } m \\
\text { (SD) }\end{array}$ & $\begin{array}{c}\text { Time in } \\
\text { home } \\
\text { sites, \% }\end{array}$ \\
\hline 1 & 21 & 4 & $40(22)$ & 86 \\
2 & 53 & 4 & $63(37)$ & 94 \\
6 & 36 & 1 & & 97 \\
7 & 35 & 4 & $1,053(732)$ & 91 \\
\hline
\end{tabular}




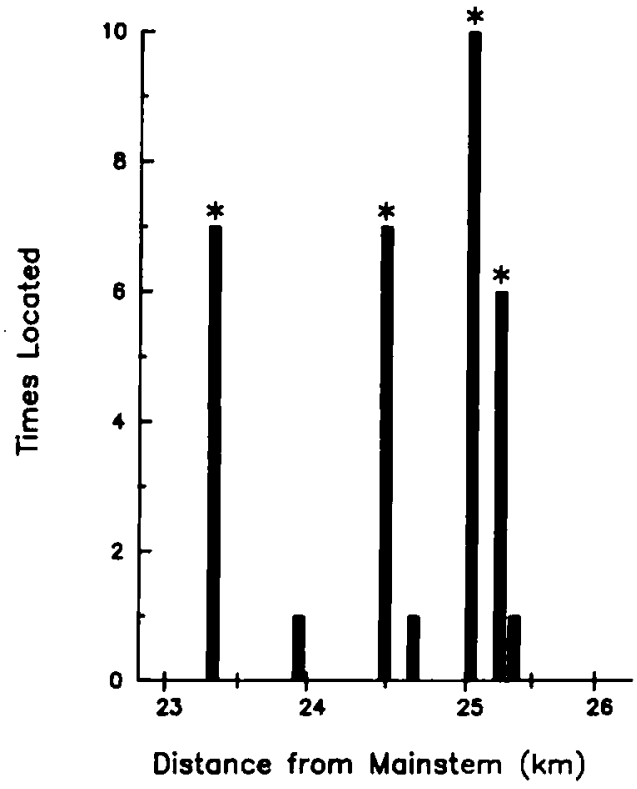

FIGURE 3. - Summer site use by fish number 7, tracked from June 1987 to May 1988. Home sites are marked with asterisks (").

presence among home sites, spending 2-3 din one before moving to another. Most of the movement between sites probably occurred at night. We observed fish moving long distances after dark on numerous occasions, and only rarely in daylight. Ninety-three percent of the instances of continuous foraging activity (often a prelude to longer movement) were observed at night.

One other brown trout (number 6) had a single home site (Table 2). It was located in that site for 52 consecutive days ( 35 observations). The fish was temporarily lost in early August 1987 , but was relocated 1 week later, approximately $18,000 \mathrm{~m}$ upstream. It remained in that upstream area until radio contact ceased (December 1987).

There was some overlap in site use by these large brown trout. Stream segments used by fish number 2 in 1986 were used on three occasions by fish number 7 in 1987. Also, fishes number 3 and 4 (tracked during autumn-winter 1986-1987) used one common segment, and fishes number 6 and 8 (tracked between 1987 and 1988) used one common segment. Although common segments were used, we never located more than one radiotagged fish in the same $10-\mathrm{m}$ segment at the same time.

Six of the eight large brown trout moved out of the area protected with no-kill fishing regulations
(Figure 2). This occurred despite the fact that none were tagged and released closer than $2 \mathrm{~km}$ from the boundaries of the area. All six of the fish that moved out of the area spent time upstream in the section of river under normal statewide regulations. Much of the movement out of the protected area occurred between November and April, when the fishing season was closed. Four of five fish tracked during the height of the fishing season (numbers 1, 2, 6 and 7) spent $87 \%$ of their time in the protected area. Fish number 8 , the widestranging fish, also spent time downstream in the area regulated with a flies-only gear restriction and a 254-mm minimum size limit.

\section{Activity}

Among individual fish, average active displacement (the distance between successive telemetry observations) ranged from 48 to $11,220 \mathrm{~m}$ (Table 3). For fishes number 4,6 , and 8 , the average distance of displacement was heavily weighted by one or two extremely long movements, but for the rest of the fish this average reflected regular movements within the range, such as the rotation among home sites described above. Active displacement was significantly greater in autumn-winter than in spring-summer $(P<0.05)$. Mean displacement for all fish tracked during spring-summer was 239 $m( \pm 2,904)$, whereas the mean displacement for all fish tracked during autumn-winter was 3,103 $m( \pm 13,174)$. Also, frequency distributions of upstream and downstream displacement for springsummer and autumn-winter were significantly different (Figure 4). Most spring-summer displacements were $50 \mathrm{~m}$ or less $(76 \%)$, whereas most autumn-winter displacements were $100 \mathrm{~m}$ or more (64\%). A regression of days between telemetry ob-

Table 3. - Active displacement of lange brown trout from one part of their range to another for two time periods. Number of measures of displacement is the number of telemetry observations minus one.

\begin{tabular}{|c|c|c|c|}
\hline $\begin{array}{c}\text { Fish } \\
\text { number }\end{array}$ & $\begin{array}{l}\text { Number of } \\
\text { measures }\end{array}$ & $\begin{array}{l}\text { Maximum } \\
\text { displace- } \\
\text { ment, m }\end{array}$ & $\begin{array}{l}\text { Mean displace- } \\
\text { ment, m (SD) }\end{array}$ \\
\hline \multicolumn{4}{|c|}{ Spring-rammer } \\
\hline $\begin{array}{l}1 \\
2 \\
6 \\
7\end{array}$ & $\begin{array}{l}20 \\
52 \\
35 \\
34\end{array}$ & $\begin{array}{r}540 \\
270 \\
16,800 \\
1,895\end{array}$ & $\begin{array}{l}48(120) \\
46(69) \\
480(2,840) \\
399(676)\end{array}$ \\
\hline \multicolumn{4}{|c|}{ Avtman-winter } \\
\hline $\begin{array}{l}3 \\
4 \\
5 \\
8\end{array}$ & $\begin{array}{l}5 \\
7 \\
7 \\
5\end{array}$ & $\begin{array}{r}460 \\
8,320 \\
1,760 \\
22,730\end{array}$ & $\begin{array}{c}160(219) \\
1,750(3,102) \\
761(670) \\
11,220(11,345)\end{array}$ \\
\hline
\end{tabular}




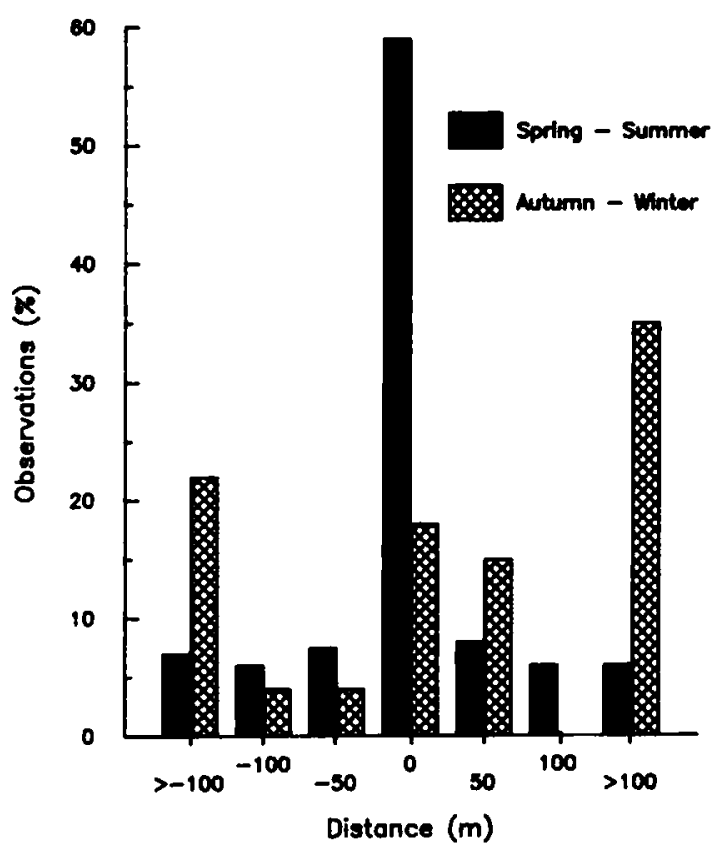

FIGURE 4.-Distributions of active displacement upstream (+) and downstream (-). Data are combined for eight brown trout tracked between May 1986 and May 1988. Number of measures (telemetry observations 1) was 141 in spring-summer and 24 in autumn-winter.

servations versus distance of active displacement was significant $(P<0.05)$, but accounted for only $11 \%\left(R^{2}\right)$ of the variation observed.

We observed no apparent upstream or downstream trends in displacement once fish took up residence in an area. However, five of six fish tracked in autumn-winter made a single, long movement, displacing themselves about $10,000 \mathrm{~m}$ upstream to the part of the river, near the town of Roscommon, considered marginal or transitional brown trout water. They remained in this upstream part of their range over winter (tracking ended in February 1987 and May 1988).

Active displacement for individual fish or individual years was not well correlated with the environmental variables we monitored. Simple and multiple linear regressions were calculated for active displacement distance versus stream discharge, daily change in stream discharge, groundwater level, daily average air temperature, daily high and low air temperatures, and day length. The best relationship was found when data for all fish and years were combined and expressed as average monthly figures. A regression of average monthly displacement versus average monthly air temperature (data from the National Weather Service station at Roscommon County Airport) and stream discharge (data from the U.S. Geological Survey) was significant $(P<0.05)$ and accounted for $69 \%\left(R^{2}\right)$ of the variation. Average stream discharge accounted for most of the variation $(68 \%)$, and this agreed with our general observation that these large fish tended to increase movement during periods of high water, such as after a heavy rain.

Foraging activity was significantly greater in August than in either June or July. Mean fluctuations in signal strength per minute of observation were 5.2 in June $(N=810), 4.9$ in July $(N=787)$, and 6.2 in August $(N=509)$. There was no significant difference between activity levels in June and July, and no significant difference in activity between years when data for all months were combined.

Significant differences between hourly activity levels within and between months reflected our observation that large brown trout exhibited regular daily cycles in foraging activity that varied seasonally. In June, four daily peaks in foraging activity were observed (Figure 5A). The time of greatest activity ( 13 fluctuations/min) was at 2200 hours, immediately after sunset. The second and third activity peaks occurred at 0100 and 0500 hours and had a magnitude of 9 fluctuations/min. The fourth peak, 7 fluctuations/min, occurred at 1430 hours. The trout were least active in late afternoon from 1600 to 1900 hours.

In July, two peaks in foraging activity were observed (Figure 5B), one at midnight (0000 hours) and one before sunrise ( 0500 hours). The midnight peak showed about the same level of activity ( 12 fluctuations $/ \mathrm{min}$ ) as the evening peak in June, but the sunrise peak in July (at 21 fluctuations/ min) was almost three times greater than the sunrise peak in June, and was the highest level of foraging activity detected during the study. The fish were relatively inactive for the rest of the day.

In August, no distinct peaks in daily activity were found (Figure 5C), but the fish were relatively active for most of the day. A low point occurred at 1100 hours, when activity dropped to 2 fluctuations $/ \mathrm{min}$. Otherwise, fish seemed to alternate between periods of high (8-10 fluctuations/min) and low (4-6 fluctuations/min) activity every 3-4 h.

\section{Habitat}

Lange brown trout selected areas with water velocities less than $10 \mathrm{~cm} / \mathrm{s}$, logs or overhanging cov- 

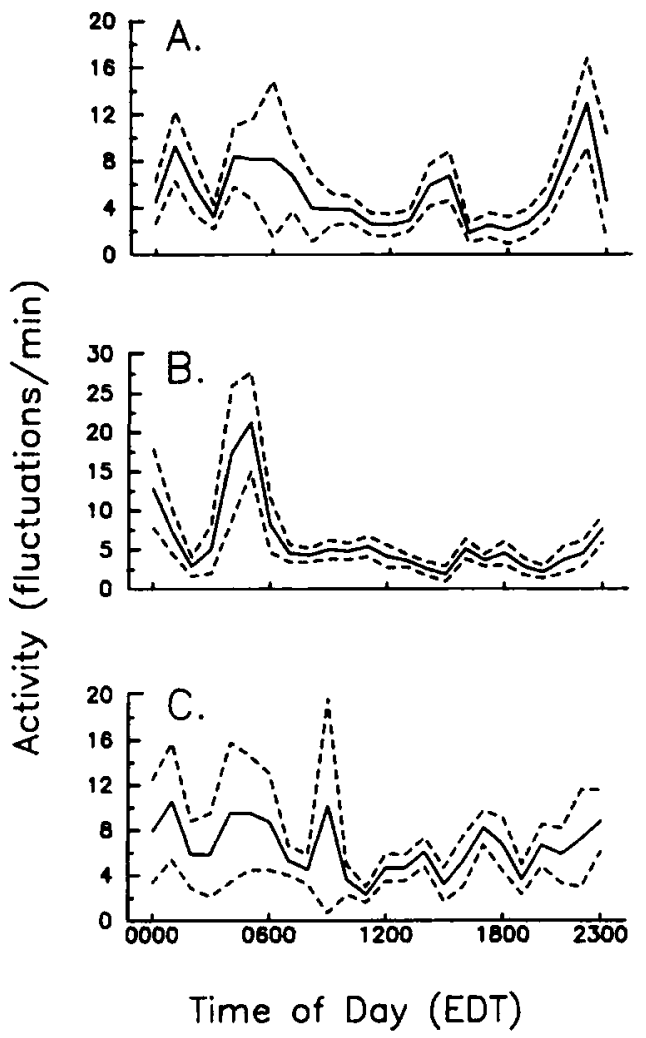

FIGURE 5. - Foraging activity pattern for brown trout tracked during (A) June, (B) July, and (C) August. Solid line represents mean activity calculated by combining observations for fish numbers $1,2,6$, and 7 (June); 2, 6, and 7 (July); and 2 and 7 (August). Dashed lines indicate $95 \%$ confidence intervals. Sunrise and sunset (eastern daylight time: EDT) occurred at about 0600 and 2115 hours (June), 0615 and 2100 hours (July), and 0645 and 2045 hours (August). Fluctuations are changes in radio signal strength caused by movement of the fish under observation.

er, silt substrate, and water depth greater than 30 $\mathrm{cm}$. In quadrats used by fish, $70 \%$ of the measures of mean water column velocity were less than 10 $\mathrm{cm} / \mathrm{s}$, whereas only $46 \%$ of velocity measures in randomly selected quadrats were that low (Figure 6). The corresponding values for bottom velocities less than $10 \mathrm{~cm} / \mathrm{s}$ were similar: $79 \%$ in quadrats used by fish and $56 \%$ in randomly selected quadrats.

Quadrats used by fish contained more cover than those selected at random (Figure 7). The habitat categories for overhang, vegetation, and log were observed at $63 \%$ of the measured points in quadrats occupied by fish, and open water was observed at $32 \%$ of the occupied points. In the randomly selected quadrats, only $32 \%$ of the points

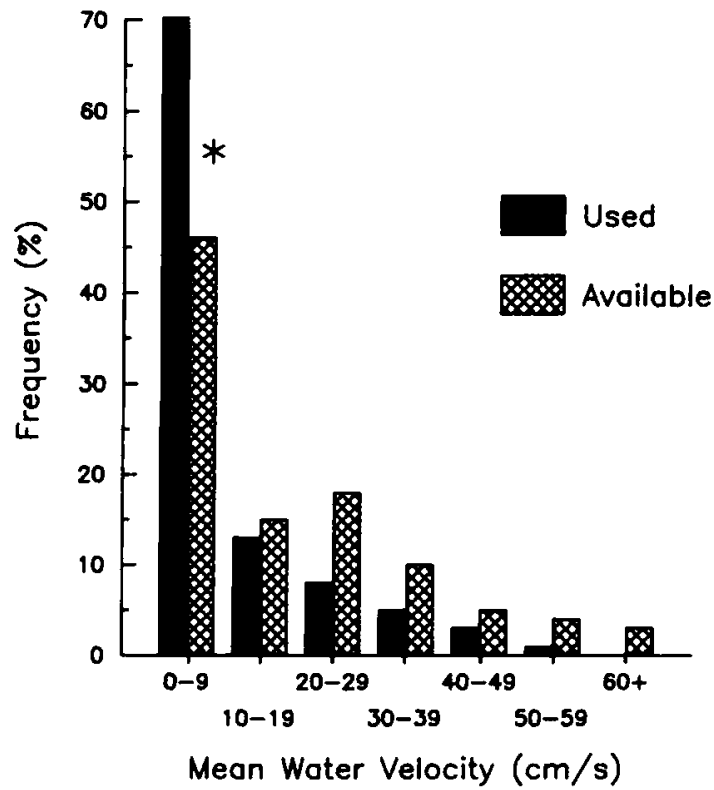

FIGURE 6. - Comparison of available mean water column velocity to that used by brown trout numbers 6,7 , and 8 , combined. An asterisk (*) indicates significant difference between velocities available and used $(P<$ $0.05)$.

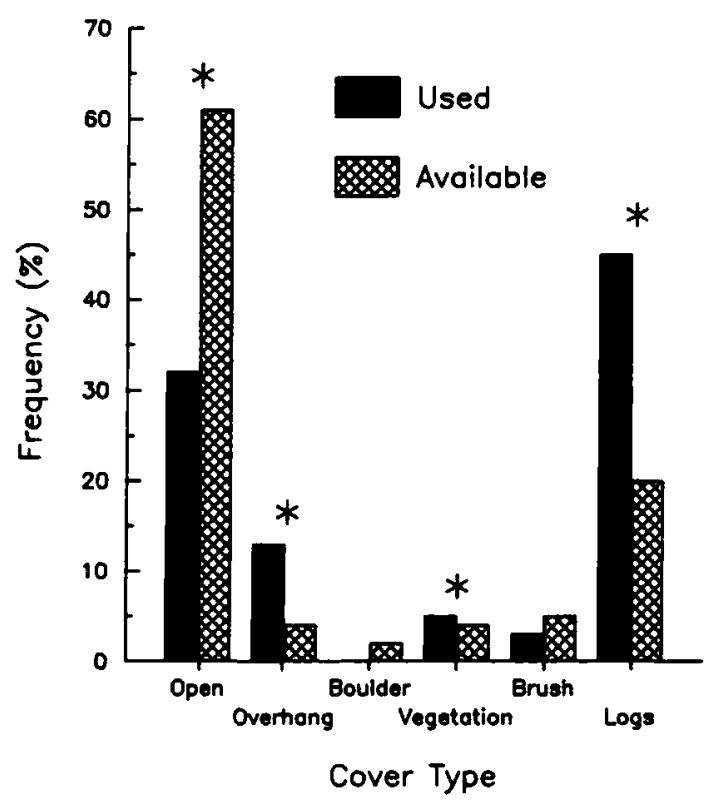

FIGURE 7.-Comparison of available cover to that used by brown trout numbers 6,7 , and 8 , combined. An asterisk $(*)$ indicates significant difference between cover types available and used $(P<0.05)$. 
measured contained overhang, vegetation, and log cover, whereas $62 \%$ contained open water.

Fish used the deepest parts of the river for their daytime refuge sites. Water deeper than $45 \mathrm{~cm}$ occurred at $46 \%$ of the measured points in the quadrats used by fish versus $35 \%$ in the random quadrats. The frequency of depth measures between $46 \mathrm{~cm}$ and $60 \mathrm{~cm}$ was significantly greater $(P<0.05)$ in quadrats used by fish.

Quadrats used by fish contained substrates with smaller particle size than did the random quadrats. Areas used by fish were predominantly (43\%) silt bottom, whereas the predominant substrate type in random quadrats was sand (32\%).

Many of the habitat variables measured in the quadrats used by fish were correlated $(P<0.05)$. Mean water column velocity was significantly correlated with water depth $(r=0.28)$ and bottom water velocity $(r=0.15)$. Substrate type was significantly correlated with mean water column velocity $(r=0.60)$, water depth $(r=0.36)$, and bottom water velocity $(r=0.43)$.

\section{Discussion}

Our results represent a quantitative description of the range, activity, and habitat of eight large brown trout, but many behavioral traits can be better expressed in qualitative terms. Large brown trout are best described as roving predators, hunting at night for less mobile prey organisms. We based this judgement on the type, extent, and timing of the movements and activity of the large fish. We could not visually observe what the fish were doing or eating in most cases, but their behavior was very different from that reported from visual observations of smaller brown trout (Jenkins 1969; Bachman 1984), and similar to behaviors of large brown trout that Jenkins (1969) observed.

\section{Assumptions}

Two basic assumptions are made in radio telemetry studies: that transmitters do not adversely affect the behavior of fish, and that the limited number of fish tracked adequately represents the behavior of the general population. The first assumption was met for the large brown trout we tracked. We saw nothing to suggest that transmitters were affecting fish behavior, and much to suggest that their behavior was unimpaired. One of our problems early in the study was high mortality of fish immediately after surgical implant. However, we later found that this mortality could be greatly reduced by using only ventral incisions and conducting all surgery when water temperature was less than $18^{\circ} \mathrm{C}$. Investigators who have used telemetry on other fishes have had similar problems. Schramm and Black (1984) reported an average mortality rate for grass carp Ctenopharyngodon idella of $31 \%$ after various surgical implant procedures, and Mulford (1984) cited various telemetric studies of striped bass Morone saxatilis in which mortality was $30-46 \%$. Both reports indicated that high water temperatures had an adverse effect on survival of fish after surgery.

The question of adequacy of sample size depends on the objectives of the study and the types of conclusions drawn. We sought to describe the behavior of large adult brown trout, and interpret that behavior in the context of existing ecological theory and fisheries management activities. We believe our sample size was adequate to do this. Individual variability in behavior was evident, but the behavior of all the fishes was consistent in a broad sense, and can be explained in the context of generally accepted ecological theory.

\section{Seasonal Behavior}

The maximum total range we found for a radiotagged brown trout was $33,420 \mathrm{~m}$. This does not seem exceptionally large, considering that distances traveled in seasonal migrations were included as part of the total range. Seasonal migrations of brown trout are well documented and have been reported to exceed $100 \mathrm{~km}$ (Jensen 1968; Jonsson 1985). Primary reasons for seasonal migrations are spawning (Jensen 1968; Solomon and Templeton 1976; Jonsson 1985; Arnold et al. 1987) and seasonal changes in water temperature or ice conditions (Avery 1983; Haynes and Nettles 1983).

Brown trout used distinctive summer and winter ranges. Fish spent most of their time during spring-summer downstream from Chase Bridge. This area had cold water temperatures in summer, as well as extensive areas of gravel substrate for autumn spawning. Over $80 \%$ of brown and brook trout spawning activity was observed in this area during a survey in November, including the aforementioned observation of a radio-tagged fish on a spawning redd.

Longer movements were characteristic of the autumn-winter period. Five of six fish tracked during this time moved about $10,000 \mathrm{~m}$ upstream to the area of the river considered marginal for trout based on summer water temperatures. This upstream area was slower and deeper than the downstream area, which might have made it better winter habitat. However, it lacked good spawning substrate and was too warm in the sum- 
mer. Fish spent most of the winter in this "marginal" area of the river.

We believe that large brown trout moved downstream of Chase Bridge to seek cooler temperatures in summer, spent most of their time in that area until they spawned in autumn, and then moved upstream to better winter habitat near Roscommon. We did not observe the downstream migration before transmitter batteries failed, but brown trout were last located in the "marginal" area as late as April, and we originally tagged these fish in the "quality" fishing area below Chase Bridge in May and June of the previous year. Brown trout have been reported to change depths or locations to seek preferred temperatures in stratified lakes (Haynes and Nettles 1983), but this behavior is not well documented for stream-resident brown trout. Previous studies (Solomon and Templeton 1976; Arnold et al. 1987) also found that brown trout, like other salmonids, generally move upstream during spawning migrations. Large brown trout in the South Branch appear to have adapted to that river's unusual combination of spawning habitat and temperature regime; the direction of current flow may be comparatively unimportant. Additional tracking during this early spring period is necessary to determine conclusively whether or not a return downstream is the typical pattern in the South Branch.

The wide-ranging seasonal movements of these large brown trout emphasize the need for a largescale river basin approach in fisheries management. The best reaches of trout streams usually receive the most attention and are often adequately protected with zoning laws, such as Michigan's Blue Ribbon Trout Streams Program. However, we found evidence in our study that marginal trout waters of the South Branch help support the largest brown trout in the river during winter, and those same fish reside in "blue-ribbon" waters during the fishing season. Moreover, areas with protective fishing regulations must be fairly large on this river, at least $5,000 \mathrm{~m}$ long, to encompass the average spring-summer range of a large brown trout.

\section{Daily Behavior}

Large brown trout used specific cover structures as central bases for nighttime foraging activity. Their general pattern in spring-summer was to remain relatively inactive in cover during daylight, move away from that site near sunset, forage sporadically throughout the night, and return to cover near sunrise. They often returned to the exact cover structure they had occupied the day be- fore, but sometimes they moved considerable distances to occupy another structure. They used this second structure in the same way as the first, as a temporary base for nighttime foraging. In this manner, they rotated among up to four home sites. The frequency and extent of these routine movements around and between home sites was greater than any previously recorded for brown trout. For example, fish number 7 was observed several times traveling up to $3 \mathrm{~km}$ in one night, that is, moving $1.5 \mathrm{~km}$ upstream and then returning downstream to the same home site by the following morning.

The homing behavior displayed by brown trout in their repeated use of home sites was different from the homing behavior associated with spawning reported by other authors. Tilzey (1977), Scholz et al. (1978), and Arnold et al. (1987) reported homing of brown trout to tributary streams for spawning, whereas the fish we studied homed to specific cover structures within a particular stream system. These structures usually covered an area of only $1-2 \mathrm{~m}^{2}$.

The habit of rotating areas of foraging activity exhibited by these large brown trout was in some ways consistent with general ecological theory on foraging in a patchy environment (MacArthur and Pianka 1966), and the manginal-value theorem of Charnov (1976), which attempts to estimate the optimal amount of time an animal should occupy and exploit a food patch before moving to another patch. The small prey fishes in the area around a home site would be the food patch in this case, and either the depletion of the small fishes or their increasing sensitivity to the presence of a predator in that area (leading to successful avoidance) could reduce the profitability of the patch.

This daily pattern of foraging activity seemed to be related to light level, food abundance, and water temperature. Other factors that might have affected foraging activity, but probably to a lesser degree, include rate of stomach evacuation (Oswald 1978), predator avoidance (Chaston 1969), and competition (Jenkins 1969). Stomach evacuation rate is related to water temperature, and both predator avoidance and competition are probably relatively minor problems for such large fish in this river. Jenkins (1969) found that agonistic behavior was the most important cause of short-range movements in the smaller brown trout and rainbow trout Oncorhynchus mykiss that he studied. But the large brown trout we studied were relatively rare (3/hectare, based on population estimates by Michigan Department of Natural Resources) and had such a size advantage over the other trout that it seems unlikely that much of 
their "foraging" activity represented agonistic behavior.

Most foraging activity from June through August occurred under low light conditions between sunset and sunrise. Maximum daily activity in June occurred near 2200 hours, and corresponded to a time of high food abundance, namely, the hatching and egg-laying period for large mayflies Ephemera simulans and Hexagenia limbata. However, even when these insects covered the surface of the river and smaller trout were surface feeding, we rarely observed surface feeding by radio-tagged brown trout. In fact, we saw them feeding on the surface less than 10 times during 2 years of observation. Their foraging activity was dominated by subsurface movements, suggesting that they were feeding primarily on other fish or emerging mayflies. They roamed the stream rather than maintaining stationary, drift-feeding stations.

Maximum foraging activity for the entire year occurred during early morning ( 0500 hours) in July. This was the coolest part of the day in the warmest month of the year. Mean minimum and mean maximum daily water temperatures in this area of the South Branch in July were $16^{\circ} \mathrm{C}$ and $22^{\circ} \mathrm{C}$, so the early morning temperatures were within the range preferred by brown trout (12.4$17.6^{\circ} \mathrm{C}$; Coutant 1977 ), whereas afternoon and evening temperatures were warmer than preferred.

Foraging activity in August was more evenly distributed throughout the day. This may have occurred due to reduced food abundance and cooler water temperatures, which could combine to cause the fish to forage more frequently. Also, during our study, water levels increased during August as a result of increased precipitation, and this could have stimulated more feeding during daylight either by reducing light levels (high, discolored water) or by temporarily increasing food abundance (washing terrestrial food items into the river).

Daily activity patterns found in other studies of brown trout varied with the environment in which the study was conducted (lake, stream, or laboratory). Swift (1962) found that brown trout in lakes were more active in daylight, commencing with a sharp rise in activity at dawn. Laboratory studies by Chaston (1969) indicated that brown trout were most active between dusk and dawn. Oswald (1978) found three daily peaks in feeding activity for brown trout in a lake, and suggested that these peaks were associated with photoperiod (dawn and dusk). In an analysis of stomach con- tents, Elliott (1970) found midday and evening peaks in feeding activity of brown trout in a stream. This variation from study to study is not surprising if activity is related to light conditions, food abundance, and temperature regimes-factors that also vary with environment.

It appears that a wide variety of habitat types is necessary to sustain large brown trout, and determination of the relative value of each type to the fish will be a difficult task. We quantitatively described daytime refuge sites, which are undoubtedly important habitats for the large fish, but we also found that they used many other habitats that were quite different from these daytime resting sites. At night, for example, large brown trout traveled into shallow riffles, deep pools, eddies, and side channels in search of prey. In general, our findings agreed with those of Shirvell and Dungey (1983) and Jenkins (1969), who found that brown trout use a variety of habitats for a variety of purposes. That is, habitats are activity-specific.

In total, our observations support the hypotheses of Shetter (1968), Jenkins (1969), and Bachman (1982) that brown trout in streams must shift from drif feeding to piscivory in order to grow to a large size. The maximum size a fish can attain by drift feeding probably varies from river to river, but based on the behavioral studies of Shetter (1968), Jenkins (1969), and Bachman (1984), the diet studies of Allen (1951), Nilsson (1957), AJexander (1977), and Stauffer (1977), and the energetics modeling study of Bachman (1982), the maximum size a brown trout can attain by drift feeding alone is probably $350-400 \mathrm{~mm}$.

\section{Acknowledgments}

We thank the Michigan Fly Fishing Club for providing the majority of funding for this study. Assistance with field work was provided by William Merrill, Kevin Gardiner, James Gapczynski, Roger Lockwood, Al Sutton, Gaylord Alexander, Jack Rogers, and Andy Nuhfer. Robert Carline, W. C. Latta, Gaylord Alexander, Andy Nuhfer, Boyd Z. Thompson, Rue S. Hestand, III, William Merrill, and Sam Williamson provided helpful comments on early drafts of this manuscript.

\section{References}

Alexander, G. R. 1977. Consumption of small trout by large predatory brown trout in the North Branch of the Au Sable River, Michigan. Michigan Department of Natural Resources, Fisheries Research Report 1855, Ann Arbor.

Allen, K. R. 1951. The Horokiwi Stream-a study of 
a trout population. New Zealand Marine Department, Fisheries Bulletin 10, Wellington.

Arnold, D. E., J. T. Nichols, and R. A. Bachman. 1987. Potamodromous spawning migrations of brown trout, with a case study from Pennsylvania. Pennsylvania Cooperative Fish and Wildlife Research Unit, Contribution 280, University Park.

Avery, E. L. 1983. Population dynamics of wild trout and associated sport fisheries in two northern Wisconsin streams. Wisconsin Department of Natural Resources Technical Bulletin 141.

Bachman, R. A. 1982. A growth model for drift-feeding salmonids: a selective pressure for migration. Pages 128-135 in E. L. Brannon and E. O. Salo, editors. Proceedings of the salmon and trout migratory behavior symposium. University of Washington Press, Seatue.

Bachman, R. A. 1984. Foraging behavior of free-ranging wild and hatchery brown trout in a stream. Transactions of the American Fisheries Society 113: 1-32.

Chamov, E. L. 1976. Optimal foraging: the marginal value theorem. Theoretical Population Biology 9: 129-136.

Chaston, I. 1969. Seasonal activity and feeding pattern of brown trout (Salmo trutta) in a Dartmoor stream in relation to availability of food. Journal of the Fisheries Research Board of Canada 26:2165-2171.

Coopes, G. F. 1974. Au Sable River watershed project biological report (1971-1973). Michigan Department of Natural Resources, Fisheries Management Report 7, Lansing.

Coutant, C. C. 1977. Compilation of temperature preference data. Joumal of the Fisheries Research Board of Canada 34:739-745.

Elliott, J. M. 1970. Diel changes in invertebrate drift and the food of trout Salmo trutta L. Journal of Fish Biology 2:161-165.

Haynes, J. M., and D. C. Nettles. 1983. Fall movements of brown trout in Lake Ontario and a tributary. New York Fish and Game Journal 30:39-56.

Jenkins, T. M., Jr. 1969. Social structure, position choice, and microdistribution of two trout species (Salmo trutla and Salmo gairdneri) resident in mountain streams. Animal Behavior Monographs 2:57-123.

Jensen, K. W. 1968. Sea trout (Salmo trutta L.) of the River Istra, western Norway. Institute of Freshwater Research Drottningholm Report 48:185-213.

Jonsson, B. 1985. Life history patterns of freshwater resident and sea-run migrant brown trout in Norway. Transactions of the American Fisheries Society $114: 182-194$.

MacArthur, R. H., and E. R. Pianka. 1966. On optimal use of patchy environment. American Naturalist 100:603-609.

Mesing, C. L., and A. M. Wicker. 1986. Home range, spawning migrations, and homing of radio-tagged Florida largemouth bass in two central Florida lakes. Transactions of the American Fisheries Society 115 : 286-295.

Mulford, C. J. 1984. Use of a surgical skin stapler to quickly close incisions in striped bass. North American Joumal of Fisheries Management 4:571-573.

Nillson, N. 1957. On the feeding habits of trout in a stream of northern Sweden. Institute of Freshwater Research Drottningholm Report 38:154-166.

Orth, D. J. 1983. Aquatic habitat measurements. Pages 61-84 in L. A. Nielsen and D. L. Johnson, editors. Fisheries techniques. American Fisheries Society, Bethesda, Maryland.

Oswald, R. L. 1978. The use of telemetry to study light synchronization with feeding and gill ventilation rates in Salmo trutta. Journal of Fish Biology 13: 729-739.

Scholz, A. T., J. C. Cooper, R. M. Horrall, and A. D. Hasler. 1978. Homing of morpholine-imprinted brown trout, Salmo trutto. U.S. National Marine Fisheries Service Fishery Bulletin 76:293-295.

Schramm, H. L., and D. J. Black. 1984. Anesthesia and surgical procedures for implanting radio transmitters into grass carp. Progressive Fish-Culturist 46:185-190.

Shetter, D. S. 1968 . Observations on movements of wild trout in two Michigan stream drainages. Transactions of the American Fisheries Society 97:472480.

Shirvell, C. S., and R. G. Dungey. 1983. Microhabitats chosen by brown trout for feeding and spawning in rivers. Transactions of the American Fisheries Society $112: 355-367$

Sokal, R. R., and F. J. Rohlf. 1969. Biometry. Freeman, San Francisco.

Solomon, D. J., and R. G. Templeton. 1976. Movements of brown trout Salmo trutta $\mathrm{L}$. in a chalk stream. Journal of Fish Biology 9:411-423.

Stauffer, T. E. 1977. A comparison of the diet and growth of brown trout (Salmo trutta) from the South Branch and the Main Stream, Au Sable River, Michigan. Michigan Department of Natural Resources, Fisheries Research Report 1845, Ann Arbor.

Strauss, R. E. 1979. Reliability estimates for Ivlev's electricity index, the forage ratio, and a proposed linear index of food selection. Transactions of the American Fisheries Society 108:344-352.

Swift, D. R. 1962. Activity cycles in the brown trout (Salmo trutta L.): I. Fish feeding naturally. Hydrobiologia 20:241-247.

Tilzey, R. D. 1977. Repeat homing of brown trout (Salmo truta L.) in Lake Eucumbene, New South Wales, Australia. Journal of the Fisheries Research Board of Canada 34:1085-1094.

Walpole, R. E., and R. N. Myers. 1985. Probability and statistics for engineers and scientists, 3rd edition. Macmillan, New York.

Winter, J. D. 1983. Underwater biotelemetry. Pages 371-395 in L. A. Nielsen and D. L. Johnson, editors. Fisheries techniques. American Fisheries Society, Bethesda, Maryland.

Received September 20, 1989

Accepted March 4, 1990 